\title{
Effect of introducing an 'afternoon pay clinic' on service utilization and cost recovery (Nepal)
}

Mahendra Pd. Shrestha

Rajesh Swar

Pradeep Panda

M.E. Khan

Population Council

Rick Homan

Follow this and additional works at: https://knowledgecommons.popcouncil.org/departments_sbsr-rh

Part of the Demography, Population, and Ecology Commons, International Public Health Commons, Public Health Education and Promotion Commons, and the Women's Health Commons How does access to this work benefit you? Let us know!

\section{Recommended Citation}

Shrestha, Mahendra Pd., Rajesh Swar, Pradeep Panda, M.E. Khan, and Rick Homan. 2007. "Effect of introducing an 'afternoon pay clinic' on service utilization and cost recovery (Nepal)," FRONTIERS Final Report. Washington, DC: Population Council. 


\title{
Effect of Introducing an 'Afternoon Pay Clinic' on Service Utilization and Cost Recovery
}

\author{
Mahendra Pd. Shrestha ${ }^{1}$, Rajesh Swar ${ }^{1}$, Pradeep Panda ${ }^{2}$, \\ M.E. Khan ${ }^{2}$, Rick Homan ${ }^{3}$ \\ ${ }^{1}$ Nepal Fertility Care Center (NFCC), Lalitpur, Kathmandu, Nepal \\ ${ }^{2}$ Population Council, FRONTIERS Program, New Delhi, India \\ ${ }^{3}$ Family Health International, FRONTIERS Program, Durham, NC USA
}

January 2007

This study is made possible by the generous support of the American people through the

United States Agency for International Development (USAID) under the terms of

Cooperative Agreement Number HRN-A-00-98-00012-00 and Population Council

Subagreement number AI05.23A. The contents are the responsibility of the Population Council and do not necessarily reflect the views of USAID or the United States Government.

\section{(f) Population Council FRONTIERS




\section{EXECUTIVE SUMMARY}

The Chhetrapati Family Welfare Center (CFWC) provided comprehensive family planning and maternal and child health (MCH) services during morning hours. Because no services were provided in the afternoon hours, full-time staff was not fully utilized. An operations research study was initiated with financial and technical assistance from the FRONTIERS Program to examine whether introducing an afternoon clinic at the CFWC with a substantially higher registration fee could improve cost recovery by adding more to program revenues than to program costs.

The project aimed to increase cost recovery from 7 percent to 10 percent by the end of the first six months of the study and then to 15 percent by the end of the subsequent six months. CFWC initiated the following services from $3-5$ p.m.: general health check-ups, OB/GYN services, immunization (including adult Hepatitis B), and family planning services. A consultation fee of Rs. 50 ( US\$0.75) was introduced for the afternoon services versus a consultation fee of Rs.10 in the morning clinic. Outreach and in-reach activities were used to raise awareness about the afternoon services among residents within the CFWC catchment area. A monitoring system was established to capture utilization, cost and revenue data.

The study showed that very few clients would use services in the afternoon clinic. The use of afternoon services remained very low (2-3 clients per afternoon as compared to 120 per day in the morning clinic). Qualitative enquiry showed that it is widely believed that family planning specialists are not the best choice for general check-up or other curative services. The provision of afternoon services generated additional revenues of Rs. 23,090 ( $\sim 344)$ for the period June 2005 to April 2006. This included laboratory revenue as well as consultation fees. The cost recovery for the first six months of the study was 6.4 percent and by the end of next six months this decreased to 5.7 percent. Both of these figures are less than the targeted cost recovery.

With a premium price of Rs. 50, the afternoon clinic can reach its cost recovery goal only if the volume of afternoon clients were to increase significantly. However, client perceptions about the ability of CFWC providers to provide non-family planning services needs to change in order for the utilization of the CFWC afternoon clinic to increase. In addition, a reduction in the price discrepancy between morning and afternoon clinics would facilitate shifting of clients from the crowded morning hours to the less crowded afternoon sessions while still helping to increase cost recovery. This could come from a reduction in the afternoon clinic fee to Rs. 25, which would be consistent with the clients' stated willingness to pay, or by increasing the morning clinic fee to Rs. 25, which would bring it in line with what clients report paying for similar services from other clinics. Both of these options are under consideration by the CFWC at the time of this report. 


\section{TABLE OF CONTENTS}

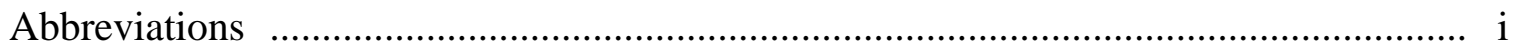

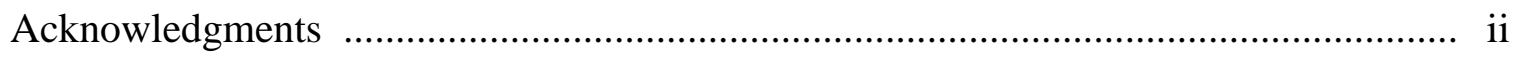

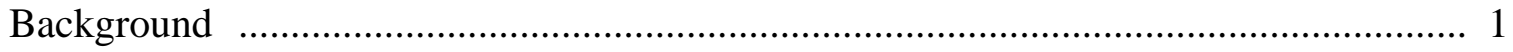

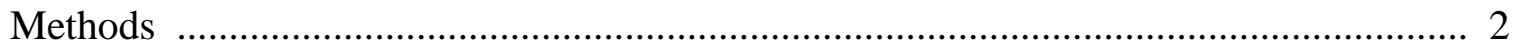

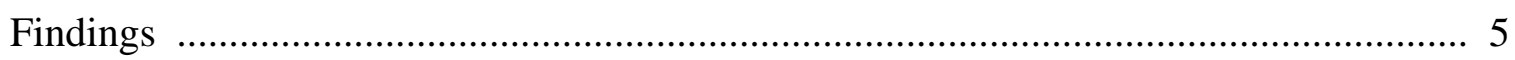

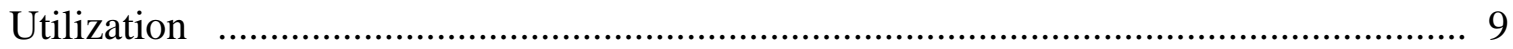

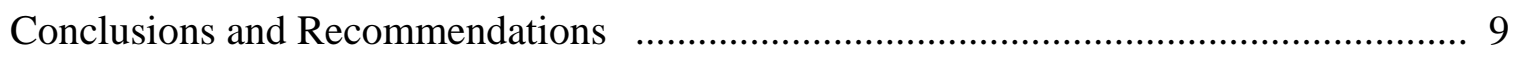

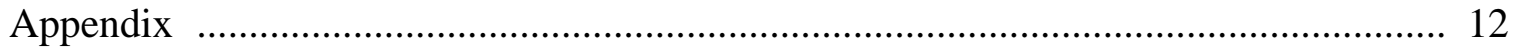




\section{ABBREVIATIONS}

$\begin{array}{ll}\text { CFWC } & \text { Chhetrapati Family Welfare Center } \\ \text { CHWs } & \text { Community Health Workers } \\ \text { DPHO } & \text { District Public Health Office } \\ \text { ENT } & \text { Ear, Nose, and Throat } \\ \text { HMG } & \text { His Majesty's Government } \\ \text { IEC } & \text { Information, Education and Communication } \\ \text { MCH } & \text { Maternal and Child Health } \\ \text { MoH } & \text { Ministry of Health } \\ \text { NFCC } & \text { Nepal Fertility Care Centre } \\ \text { NGO } & \text { Non Governmental Organization } \\ \text { OB/GYN } & \text { Obstetrics/Gynecology } \\ \text { SDPs } & \text { Service Delivery Points } \\ \text { USAID } & \text { United States Agency for International Development } \\ \text { VHWs } & \text { Village Health Workers }\end{array}$




\section{ACKNOWLEDGMENTS}

We are thankful to the FRONTIERS Program of The Population Council for having funded this project, and for helping us to build our capacity to conduct financial sustainability research. We are grateful to HMG's National Health, Education, Information and Communication Center for helping to promote the afternoon clinic. We are grateful to the Director General, Department of Health Services, Ministry of Health and Population and the many Village Health Workers and Community Health Workers who helped spread the word about the new afternoon clinic. Our sincere thanks go to Dr. M.E. Khan, Regional Associate Director, FRONTIERS Program, Population Council; Dr. Rick Homan, Senior Associate for Health Economics, Family Health International; and Dr. Pradeep Panda, Fellow in Economics, Population Council for providing training, technical support, and guidance to carry out this research project. Finally thanks are due to Dr. James Foreit of the Population Council and Dr. Barbara Janowitz and Mr. John Bratt of Family Health International for extensive review and comments, which considerably improved this report. 


\section{BACKGROUND}

One of the key activities of the FRONTIERS Program is to train and help NGOs build their capacity to use OR and financial data to make programmatic decisions designed to reduce dependence on donors. A regional workshop was held in India in 2004, where three NGOs, one each from Bangladesh, India and Nepal were helped to develop OR proposals that were subsequently funded by FRONTIERS. On-going technical assistance was provided to help the organizations apply skills for improving financial sustainability. One of the participants was the Nepal Fertility Care Center (NFCC) in Kathmandu, Nepal. This report describes the study they undertook.

The Chhetrapati Family Welfare Center (CFWC) provides comprehensive family planning and $\mathrm{MCH}$ services in addition to clinical training in family planning and $\mathrm{MCH}$ services to government and NGO employees. Prior to this study, the clinical services were offered five days per week during morning hours $(8: 00-1: 30 \mathrm{pm})$ with a uniform registration fee of Rs. 10 . Laboratory services were also available but at an additional cost to the client.

Because services were offered only in the morning hours, the clinic was often very crowded during the morning but during the afternoon the service providers were not very busy. Even though the clinic remained fully staffed throughout the afternoon hours, the providers would be sitting in the clinic with no clients to serve and were therefore underutilized. In terms of efficiency, this means that the fixed cost of labor, equipment, and infrastructure can only be spread across the clients served during the morning hours. In addition, the low registration fee means that there is limited scope for generating revenues that can be used to offset program costs. In 2005, user fees covered only 7.3 percent of program costs with the balance covered by USAID.

In order to improve cost recovery, NFCC proposed the introduction of an afternoon clinic with a registration fee of Rs. 50. The Rs. 50 fee was selected keeping in mind the fees typical in private clinics and the difficulties encountered when changing fees at the CFWC. Changing fees at the CFWC requires government approval and obtaining such approval is difficult and time consuming. Therefore it was felt it was better to request a large increase rather than have to go back in 6-12 months and request another increase.

If clients can be attracted to the afternoon clinic, the fixed resources of CFWC would be more fully utilized, and program revenues and thereby cost recovery would increase. The extent to which the afternoon clinic will help in increasing cost recovery would depend on two factors: client demand for services and any additional costs incurred to support afternoon service provision. The purpose of the intervention was to increase cost recovery from 7 to 10 percent by the end of the first six months of the study and then to 15 percent by the end of the next six months of the study.

Research Questions: The objective of this study was to examine whether the introduction of afternoon clinic services could improve the cost recovery of the CFWC. Specific research questions included: 
1. What is the potential client demand for afternoon services?

2. What is the utilization of the afternoon services?

3. What is the variable cost and contribution margin for each of the afternoon services?

4. If the donors were to continue to cover the cost of supplies, will the additional revenue from afternoon services be sufficient to meet cost recovery objectives?

5. What would happen to cost recovery if the government and/or donors reduced the amount that is paid to cover the cost of supplies?

\section{METHODS}

To evaluate the impact of introducing afternoon clinic services, a simple post-test only design was used. A comprehensive monitoring system was put in place to document the quantity of visits to the afternoon clinic and record the service(s) received and revenues collected.

\section{Interventions:}

- Introduction of the afternoon clinic: CFWC offered the following services in the afternoon clinic (3 - 5 pm) beginning in mid-June 2005:

1. General Health Check-up

2. OB/GYN

3. Child Immunizations

4. Adult Hepatitis B immunization

5. Family Planning

The morning clinic continued to provide these services at a fee of RS 10, except for the general health check-up, which was moved to the afternoon clinic. All adult Hepatitis B clients were now referred to the afternoon clinic. CFWC introduced an increased consultation fee of Rs. 50 ( US\$0.75) ${ }^{1}$ as compared to the morning clinic consultation fee of Rs. 10. The laboratory fees remained unchanged for both the morning and afternoon clinics.

- Marketing of the afternoon clinic: To promote the afternoon clinic and increase the volume of clients, "in-reach" and "outreach” marketing strategies were used. Sixty banners, 4,500 posters and 45,000 pamphlets were displayed and distributed at different strategic locations of the Kathmandu Municipality area and were replaced by new banners/posters once they were torn down, removed and/or worn out.

Posters were prominently exhibited in the reception area of the clinic so that each client would know about the availability of the new services. Pamphlets describing fee details and availability of services provided in the afternoon clinic were also distributed to the clients in the morning clinic.

\footnotetext{
${ }^{1}$ http://www.oanda.com/convert/fxhistory accessed on 5/9/06 for period June 14, 2005 - April 30, 2006. The average exchange rate for the period is 67.16 Nepali Rs. per US dollar.
} 
Posters and pamphlets were also displayed and distributed in different clinics and local pharmacies with their concurrence. In addition, posters and pamphlets were distributed to many Village Health Workers (VHWs) and Community Health Workers (CHWs) after providing them with complete information about the new service hours and availability of services in the afternoon clinic during their meeting at CFWC.

A meeting was organized with key stakeholders including: municipality officials, ward members, social workers, intellectuals, doctors, service providers, media and local pharmacies to let them know about the new afternoon clinic services and fee details.

Additionally, a meeting was organized under the chairmanship of the Director General, Department of Health Services, Ministry of Health and Population to let officials know about the initiation of the afternoon service. The meeting decided that the afternoon clinic information should be disseminated through HMG's regular National Health, Education, Information and Communication Center's program. Accordingly, the afternoon clinic initiative was telecast through Nepal Television in November 2005 and broadcast twice through Radio Nepal that same month (five months after the opening of the afternoon clinic).

Any costs associated with the marketing of the afternoon clinic were paid for from project funds rather than from clinic revenues.

\section{Data Sources:}

Interview of clients in morning session: The study interviewed 300 morning clients through a structured questionnaire from July 8, 2005 to August 7, 2005. The main objective of the client interview was to obtain information on the types of health problems for which services were sought. In addition, the interview captured information on services that were obtained from elsewhere and the price paid for those services as well as information on clients' willingness to pay for afternoon services.

The total number of clients that had visited the Center during this period was 2,188. This figure was considered the universe from which a convenience sample of 300 clients was drawn. All the enumerators obtained informed consent before proceeding to an interview. The participant was fully informed about the purpose of the study, risks and benefits to the study participant, information on confidentiality including the use of identifiers and access to personal data, where to go with questions or problems at any time, and information on study procedure and duration.

Qualitative interview with clients: Clients' views on use of the afternoon clinic were assessed by in-depth interviews with five morning clients and five afternoon clients (two clients had shifted from morning to afternoon, one client who had shifted from afternoon to morning, and two clients who were new to the afternoon clinic).

Service statistics of afternoon session: The study collected afternoon service statistics separately and examined utilization in five categories: general health check-up, OB/GYN, immunization, Hepatitis B, and family planning. These data were used to document the mix of 
services that clients accessed in the afternoon clinic and any fees paid by the afternoon clients (registration and laboratory).

Interview with providers and observation of service delivery: The project coordinator interviewed service providers and/or observed delivery of services to obtain a list of the non-joint supplies required for the provision of these services.

Financial records of the clinic: Data from CFWC financial systems were used to compute the total clinic costs, total clinic revenues and the cost recovery percentage for the six-month period from May to October 2005, and for the six-month period from November 2005 to April 2006.

\section{Outcomes:}

1. Services Desired: The client interview asked clients to identify both the services they were receiving but also other services that they would like to be able to receive from the CFWC.

2. Attitude towards Afternoon Clinic: The qualitative interview explored the reasons clients would or would not use afternoon services. This can help guide decisions about the future marketing of the afternoon clinic.

3. Use of Afternoon Clinic: Data from the clinic registration book indicated which service(s) were received by the afternoon clients and the fees paid for registration and laboratory services.

4. Contribution Margin: The contribution margin is the difference between the fee collected and the average variable cost of providing the service. The contribution margin indicates that part of the fee that can be used to offset the fixed cost of service provision.

5. Cost Recovery Percent: The cost recovery percent is computed as the total program revenues collected in a period divided by the total program costs from the same period.

\section{Analyses:}

In order to assess the potential demand for new services, we evaluated the frequency distribution of services desired, along with data on willingness to pay for afternoon services, the current fees paid for services received from other clinics, and the satisfaction with CFWC services. All of these data come from the interview with morning clients. In addition, data from the qualitative interviews with clients provide information on the potential obstacles to use of the afternoon clinic that will need to be addressed if this intervention is to be successful.

The utilization of afternoon services was assessed by examining data from the clinic registry. This allowed analysis of which services were most popular in the afternoon clinic as well as the volume of clients served per clinic afternoon.

NFCC also undertook a costing exercise to identify the variable cost components of the afternoon services (additional supplies required to deliver services). Because the CFWC has been receiving supplies at no cost from donors or the $\mathrm{MoH}$ district stores, from the perspective of the CFWC, the average variable cost of service provision is zero. However, from the $\mathrm{MoH}$ or donor perspective, there is a cost to these resources. The ideal price to use in this analysis would 
be the cost to the $\mathrm{MoH}$ or the donor but attempts to procure that information proved unsuccessful. Therefore, the local market prices were used instead ${ }^{2}$.

By comparing the fee collected to the average variable cost of service provision, it can be determined whether serving an additional client in the afternoon clinic adds more to program revenues or to program costs (contribution margin analysis). Finally, cost recovery percentages for the first 6 months of the project period and the subsequent six months of the project period were computed to assess whether or not the revenue goals were achieved.

\section{FINDINGS}

\section{Demand for new services}

The interviews with morning clients indicated a general interest in having afternoon clinics that would offer a wider array of services. The types of services desired were dominated by curative services (Table 1).

Table 1: Services desired by the clients in the afternoon clinics

\begin{tabular}{|l|c|}
\hline \multicolumn{1}{|c|}{ Service } & Percentage (N=300) \\
\hline ENT & 68 \\
\hline Delivery & 58 \\
\hline Eye & 49 \\
\hline Orthopedic & 34 \\
\hline General Health Check-Up & 33 \\
\hline Pediatrics & 28 \\
\hline Dermatology & 25 \\
\hline Chest & 17 \\
\hline Dental & 14 \\
\hline Gastroenteritis & 8 \\
\hline Multiple responses permitted &
\end{tabular}

The median fee that clients reported they were willing to pay for afternoon services was Rs. 27, which was substantially less than the afternoon clinic fee of Rs. 50.

The survey of 300 morning clients indicated that many had used other providers for health services including: health check-up (92 percent), blood test (66 percent), stool/urine test (60 percent), X-Ray (32 percent), delivery (31 percent), ultrasound (21 percent), dental (4 percent), family planning (4 percent), and ultrasound (21 percent). The median fee paid by clients for these services was Rs. 50, which was in keeping with the selected fee for the afternoon clinic.

The survey found that 68 percent of the morning clients had visited CFWC several times and 99 percent would recommend CFWC to others. Two main factors contributed to this response: low fees and perceived service quality at CFWC. Almost two-thirds of the respondents (63 percent) stated that it was relatively cheaper to obtain services from CFWC than other private clinics.

\footnotetext{
${ }^{2}$ One known problem with the proxy was that the contraceptive commodity prices were subsidized by the donors through the social marketing program and therefore were lower than the full cost to the donors.
} 
Similarly, 74 percent of the respondents were "highly satisfied" and 24 percent were "satisfied" with service delivery.

\section{Qualitative assessment of client's view on afternoon clinic}

Analysis of the qualitative data revealed that only 7 of the 10 informants were aware of a difference in the registration fee between morning and afternoon clinics. Four of the five clients who attended the afternoon clinic were aware of the difference in fee and were willing to pay the higher fee because of less waiting time and because the afternoon clinic hours were more convenient.

The two clients who had shifted from the morning to the afternoon clinic were not aware of the difference in registration fee between the morning and afternoon hours. Once they were informed, they decided that henceforth they would use the morning clinic, as the fee difference was too high. Three of the five informants who preferred the morning clinic knew about the difference in registration fee and felt that Rs.50 was too expensive to avail services at the afternoon clinic.

In general, the qualitative enquiry revealed that clients for whom the timing of the morning clinic was less convenient, would be the main users of the afternoon clinic. However, if the afternoon registration fee were reduced to Rs. 25, more clients indicated a willingness to use afternoon services. This result is consistent with the willingness to pay survey results reported above.

Beside cost, a serious obstacle to clients using the afternoon clinic was the CFWC's image as a "family planning clinic," and the doctors working there being perceived as "family planning specialists." Seven of the 10 informants who were interviewed mentioned their reluctance to use a "family planning specialist" for a general health check-up.

\section{Utilization of the afternoon clinic and services}

Of the 429 client visits to the afternoon clinic during the study period, over 60 percent were for family planning services or obstetrics/gynecology services. The remaining visits were for Hepatitis B injection, immunization, or general health check-up (Table 2). For a monthly breakdown of services see Appendix.

Table 2: Distribution of Client Visits to Afternoon Clinic (14 June, 2005 through 30 April, 2006)

\begin{tabular}{|l|c|c|}
\hline \multicolumn{1}{|c|}{ Service } & No. of Visits & Percentage \\
\hline Family Planning & 156 & 36 \\
\hline Obstetrics / Gynecology & 105 & 25 \\
\hline Hepatitis B Injection & 103 & 24 \\
\hline Immunization & 36 & 8 \\
\hline General Health Check-Up & 29 & 7 \\
\hline Total & $\mathbf{4 2 9}$ & $\mathbf{1 0 0}$ \\
\hline
\end{tabular}


Sixty-five (15 percent) of the clients served in the afternoon were clients that had previously received services in the morning clinic where fees were lower. According to the clinic director, possible reasons for the shift to the more expensive clinic include: a) attempt to avoid loss of family planning protection (primarily Depo Provera users), b) not wanting to queue for services, c) perceived difference in service quality (the morning clinic is viewed as a government service outlet compared to the afternoon clinic which may be considered similar to a private facility), and d) afternoon time was more convenient.

Overall, the uptake of the afternoon clinic services was very low, on average 2.1 clients per day, compared to an average of 120 clients per day in the morning clinic.

\section{Variable cost and contribution margin of services}

Since one goal of the afternoon clinic was to improve the financial sustainability of CFWC, it was important to assess whether the additional revenue collected would be sufficient to offset the additional costs associated with the provision of services. The contribution margin (the difference between the fee collected and the average variable cost) indicated whether or not the provision of services would help offset the fixed costs associated with CFWC.

While the fee collected was easily identified, the average variable cost of providing the service depended upon the perspective being used for the analysis. Currently CFWC is not paying for any of their administrative, clinical, or laboratory supplies and therefore the variable cost of service provision to CFWC is zero. This means that the CFWC's contribution margin was equal to the fee charged for the services (Rs. 50 for the afternoon visits plus the lab fee for any lab services utilized).

However, if the value of the supplies used by CFWC to provide services is considered, which represent resources that must be provided from the Ministry of Health District Stores or donors, then the contribution margin is reduced. In the case of family planning services, the contribution margin is negative due to the high cost of commodities (particularly Norplant). Table 3 below provides a summary of the estimated average variable cost per client and the contribution margin by type of service from the perspective of CFWC (column 2) and from the provider of the supplies (column 4).

If the afternoon clinic did not charge the increased fee of Rs.50, and charged the same Rs. 10 fee as the morning clinic, then only general health check-ups and Hepatitis B injection services would be able to cover the average variable costs of service provision; all the other services would generate net losses to the program. 
Table 3: Estimated Average Variable Cost per Client and Contribution Margin by Type of Service

\begin{tabular}{|l|c|c|c|}
\hline \multicolumn{1}{|c|}{ Service } & Fee (Rs.) & $\begin{array}{c}\text { Avg. Variable } \\
\text { Cost (Rs.) }\end{array}$ & $\begin{array}{c}\text { Contribution } \\
\text { Margin (Rs.) }^{3}\end{array}$ \\
\hline Family Planning Services $(\mathrm{n}=156)$ & 50 & $105.0^{*}$ & $-55^{*}$ \\
Lab & $0.3^{*}$ & $0.1^{*}$ & $0.2^{*}$ \\
Overall & $50.3^{*}$ & $105.1^{*}$ & $-54.8^{*}$ \\
\hline OB/GYN Services $(\mathrm{n}=105)$ & 50 & 20.9 & 29.1 \\
Lab & $15.2^{*}$ & $7.8^{*}$ & $7.4^{*}$ \\
Overall & $65.2^{*}$ & $28.7^{*}$ & $36.5^{*}$ \\
\hline Hepatitis B Injection $(\mathrm{n}=103)$ & 50 & $3.5^{4}$ & 46.5 \\
\hline Immunization (n=36) & 50 & $31.1^{*}$ & $18.9^{*}$ \\
\hline General Health Check-Up $(\mathrm{n}=29)$ & 50 & 0.7 & 49.3 \\
\hline
\end{tabular}

${ }^{1}$ From the CFWC perspective, this is the contribution margin since they receive all supplies at no cost.

${ }^{2}$ This reflects the value of administrative, clinical, and laboratory supplies used to provide services based upon local market procurement as a proxy for cost to $\mathrm{MoH} /$ Donors.

${ }^{3}$ Contribution margin is defined as fee minus the average variable cost; taking into account the cost of administrative, clinical and laboratory supplies required to provide the services.

* Average across multiple afternoon clients.

${ }^{4}$ Average variable cost is low since the client must procure the vaccine from market.

\section{Extent of cost recovery, if donors provide all variable costs}

Currently, USAID and District Public Health Office (DPHO) of the Ministry of Health and Population contribute all the costs pertaining to service provision at CFWC. There is no additional cost to CFWC involved in the provision of afternoon services.

The 429 afternoon clinic visits generated Rs. 23,090 ( $\$ 344)$ in additional revenues for the CFWC during the study period. This represents an average contribution margin of Rs. 53.8 per visit (Rs. 23,090 $\div$ 429). Despite this positive contribution margin, due to the low volume of clients, the total additional revenue generated was very small as compared to the total cost of clinic operations. Table 4 summarizes the total costs and total revenues earned by CFWC for the first 6-months and the next 6-months of the project. The cost recovery and the targeted cost recovery are given in the last two columns.

Table 4: Analysis of cost recovery performance for first 6 months and last 6 months of project period

\begin{tabular}{|c|l|c|c|c|c|c|}
\hline S. No. & \multicolumn{1}{|c|}{ Period } & $\begin{array}{c}\text { Total Cost } \\
\text { (Rs.) }\end{array}$ & $\begin{array}{c}\text { Total } \\
\text { Revenue } \\
\text { (Rs.) }\end{array}$ & $\begin{array}{c}\text { Cost } \\
\text { Recovery } \\
\text { Percent }\end{array}$ & $\begin{array}{c}\text { Target } \\
\text { Percent }\end{array}$ & $\begin{array}{c}\text { Percent } \\
\text { of Target } \\
\text { Achieved }\end{array}$ \\
\hline 1 & May-October 2005 & $3,557,706$ & 226,015 & 6.4 & 10 & 64 \\
\hline 2 & November 2005 - April 2006 & $3,303,070$ & 189,890 & 5.7 & 15 & 38 \\
\hline
\end{tabular}

The cost recovery obtained was approximately 64 percent of the target in the first project period and 38 percent in the second project period. Assuming the average contribution margin of Rs. 53.8 computed above, the CFWC would have needed to attract an additional 22 afternoon clients per clinic day during the May-October 2005 period to reach 10 percent cost recovery. For the second period, November 2005 - April 2006, the CFWC would have needed to attract an additional 51 afternoon clients per clinic day. While the staffing and physical capacity could handle this client load, the challenge is the successful marketing of the afternoon clinic. 


\section{Extent of cost recovery if variable costs are covered by the CFWC}

If all resources (e.g., additional administrative, clinical, and laboratory supplies) are to be provided by CFWC, the situation of cost recovery will be quite different. The results of this analysis will be relevant to the $\mathrm{MoH}$ if they want to consider replicating the introduction of afternoon clinic services to other urban service delivery points in Kathmandu Valley.

Using the contribution margins from Table 3 and the mix of services provided in the afternoon clinic from Table 2, it can be seen that the overall contribution margin falls from Rs. 53.8 to Rs. 5.1 when the cost of supplies are considered (Table 5). This is primarily because of the large negative contribution margin per visit for family planning services (primarily due to the high cost of Norplant).

Table 5: Performance of Afternoon Clinic
When Value of Supplies Are Considered
\begin{tabular}{|l|r|c|}
\hline \multicolumn{1}{|c|}{ Service } & $\begin{array}{c}\text { No. of } \\
\text { Visits }\end{array}$ & $\begin{array}{c}\text { Contribution } \\
\text { Margin per } \\
\text { Visit (Rs.) }\end{array}$ \\
\hline Family Planning & 156 & -54.8 \\
\hline Obstetric / Gynecology & 105 & 36.5 \\
\hline Hepatitis B Injection & 103 & 46.5 \\
\hline Immunization & 36 & 18.9 \\
\hline General Health Check-Up & 29 & 49.3 \\
\hline Total & $\mathbf{4 2 9}$ & $\mathbf{5 . 1}$ \\
\hline
\end{tabular}

With this small positive contribution margin, the 429 afternoon clinic visits would generate only Rs. 2,183 (\$32.50) as net revenue. This would have minimal impact on offsetting the high fixed costs of the CFWC.

\section{UTILIZATION}

As a result of participating in this study, which was related to the capacity building efforts of FRONTIERS, three CFWC staff gained experience in estimating the cost of services and the use of contribution margin analyses to assess the potential for cost recovery from increasing the fees and/or the use of services. Since NFCC is engaged in a number of training activities, they are positioned to undertake similar analyses of their training programs using some of the same techniques.

\section{CONCLUSIONS AND RECOMMENDATIONS}

Like many government clinics, the CFWC currently suffers from the problem of services priced below the average variable cost of producing the service. In this case, each client served adds more to the total costs of the program than to the total revenues (a negative contribution margin) so each additional client served increases the operational deficit of the program. With growing 
populations, the budgetary requirements are unable to keep pace with the demand for services and the result is often inconsistent availability of services due to supply shortages.

The study showed that premium pricing of afternoon services generated very little additional demand for services. Plausible reasons for the small uptake of afternoon services include: 1) an unacceptably high service fee, 2) competition in providing non-family planning services within Kathmandu municipality, 3) adequate access of services even in the periphery of municipality, 4) limited awareness outside of regular clients of CFWC, and 5) perception by potential clients that CFWC is only a family planning clinic. Potential clients have concerns about receiving nonfamily planning services from those they perceive as family planning doctors. Therefore, CFWC would need to educate potential clients about the skills and experience of CFWC doctors in providing non-family planning services.

It may also be useful to request the Ministry of Health to periodically provide marketing support for afternoon services in its ongoing health program advertisements through TV and radio, a major and key component of the National Health Information, Education and Communication (IEC) initiatives. The advertisements were associated with a spike in demand (see Appendix), but there may be other seasonal effects not accounted for behind the spike in December.

The cost recovery objective of this project was not achieved. Even though there was no additional cost to CFWC for the provision of afternoon services, low client flow limited the ability to generate revenues from the afternoon clinic. CFWC may want to consider lowering the afternoon fee to Rs.25, close to what the willingness to pay survey suggests. For this strategy to be effective, CFWC must be confident that client uptake of afternoon services would more than double since the fee would be reduced by $50 \%$. An alternative strategy to reduce the price discrepancy between morning and afternoon clinics would be to increase the registration fee in the morning clinic to Rs. 25. Alternatively, a uniform fee of Rs. 25 could be introduced for both the morning and afternoon clinic and thus remove the financial incentive to crowd the morning clinic and bring the fees in line with the results of the willingness to pay survey of clients. This highlights the potential benefit of conducting a willingness to pay survey prior to introducing a price increase.

At Rs. 50, CFWC could recover variable costs even if it had to buy contraceptive products and provide other supplies. However, in the morning clinic, the registration fee of Rs. 10 is insufficient to cover the variable cost of service provision. Unless a third-party can be relied upon to pay for these supplies, each client served will add more to program costs than to program revenues and thereby increase the operating deficit. This highlights the basic problem of sustainability of services when fees have been set below the cost of the supplies required to provide the services.

Current clients have indicated a desire to have other health services available from CFWC. However those services tend to be unrelated to reproductive health. Recent attempts to introduce pediatric services failed, as CFWC could not find a pediatrician willing to provide services one afternoon per week under a revenue sharing arrangement. Any new services that are considered for introduction must also consider the skills of the available CFWC staff otherwise there would be additional fixed costs (labor) associated with expanding the mix of services offered. 
To conclude, besides building capacity of NFCC in financial decision making, the study lead to the following lessons learned:

1. Family planning program sustainability without external support would not be feasible in the near future. While the other services could generate positive contribution margins if priced at Rs. 50 (see table 5), family planning services would still generate net losses.

2. At a uniform price of Rs. 25 per service, CFWC could improve cost recovery. However, in order to achieve any meaningful improvement in cost recovery, it is imperative to increase service demand for the non-family planning services to offset the deficit generated from each family planning client served.

3. Looking at costs versus revenues from the Ministry of Health perspective, the idea of introducing premium 'pay-for-service' services in afternoon hours is financially feasible since the revenue earned would be greater than the additional costs incurred for supplies. This assumes that there would continue to be sufficient numbers of non-family planning clients served to offset the negative contribution margin associated with each family planning client served (see Table 5). 


\section{APPENDIX}

Distribution of Afternoon Clinic Visits by month $(\mathrm{N}=429)$

(14 June 2005 - 30 April 2006)

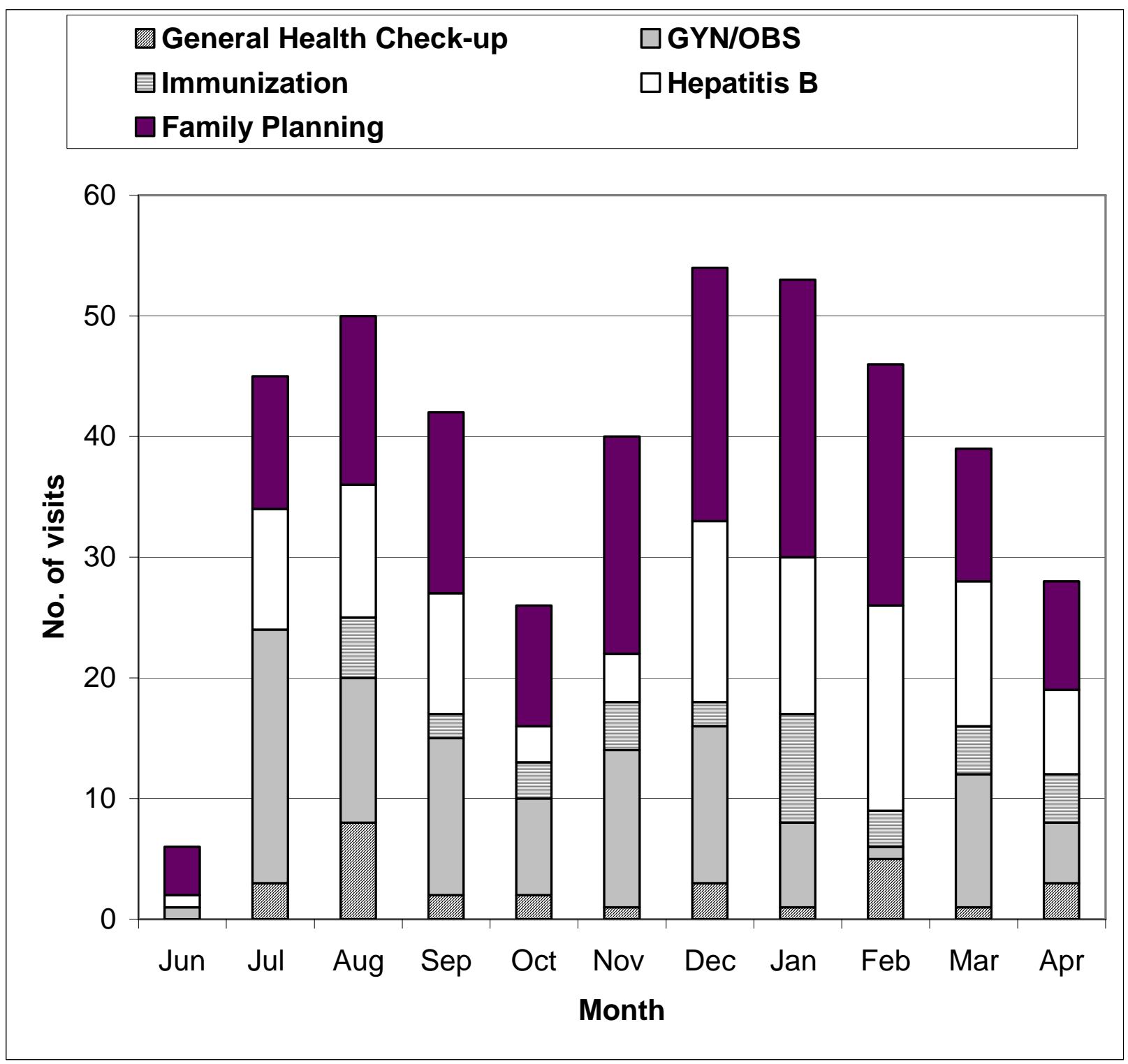

